\title{
Increased Risk of Neoplasms in Adult Patients Undergoing Interval Appendectomy
}

\author{
Jungtack Son*, Yong Jun Park*, Sung Ryol Lee, Hyung Ook Kim, Kyung Uk Jung \\ Department of Surgery, Kangbuk Samsung Hospital, Sungkyunkwan University School of Medicine, Seoul, Korea
}

Purpose: The low rate of recurrent appendicitis after initial nonsurgical management of complicated appendicitis supports the recently implemented strategy of omitting routine interval appendectomy. However, several reports have suggested an increased incidence rate of neoplasms in these patients. We aimed to identify the risk of neoplasms in the population undergoing interval appendectomy.

Methods: This study retrospectively analyzed consecutive cases of appendicitis that were treated surgically between January 2014 and December 2018 at a single tertiary referral center. Patients were divided into 2 groups depending on whether they underwent immediate or interval appendectomy. Demographics and perioperative clinical and pathologic parameters were analyzed.

Results: All 2,013 adults included in the study underwent surgical treatment because of an initial diagnosis of acute appendicitis. Of these, 5.5\% (111 of 2,013) underwent interval appendectomy. Appendiceal neoplasm was identified on pathologic analysis in 36 cases (1.8\%). The incidence of neoplasm in the interval group was 12.6\% (14 of 111), which was significantly higher than that of the immediate group $(1.2 \%$ [22 of 1,902$], \mathrm{P}<0.001)$.

Conclusion: The incidence rate of neoplasms was significantly higher in patients undergoing interval appendectomy. These findings should be considered when choosing treatment options after successful nonsurgical management of complicated appendicitis.

Keywords: Appendicitis; Interval appendectomy; Neoplasms

\section{INTRODUCTION}

Appendicitis is one of the most common abdominal emergencies worldwide. Since the first publication describing acute appendicitis by Fitz in 1886, surgical management of appendicitis has been considered a standard practice [1]. Appendectomy is the most commonly performed abdominal surgery, and the lifetime chance of

Received: Aug 30, 2019 - Revised: Oct 4, 2019 - Accepted: Oct 15, 2019 Correspondence to: Kyung Uk Jung, M.D.

Department of Surgery, Kangbuk Samsung Hospital, Sungkyunkwan University School of Medicine, 29 Saemunan-ro, Jongno-gu, Seoul 03181, Korea

Tel: +82-2-2001-8408, Fax: +82-2-2001-8360

E-mail: sahelgrean@gmail.com

ORCID: https://orcid.org/0000-0002-8844-3724

*Jungtack Son and Yong Jun Park contributed equally as co-first authors.

(c) 2020 The Korean Society of Coloproctology

This is an open-access article distributed under the terms of the Creative Commons Attribution NonCommercial License (https://creativecommons.org/licenses/by-nc/4.0) which permits unrestricted noncommercial use, distribution, and reproduction in any medium, provided the original work is properly cited. requiring appendectomy in the Korean population is about $8 \%$ [2]. However, over the last 2 decades, although the treatment of choice for uncomplicated appendicitis remains immediate surgery, the gold standard treatment of complicated appendicitis presenting with abscess or phlegmon has shifted toward conservative nonsurgical management, consisting of antibiotic administration with or without interventional drainage. Compared with immediate appendectomy, nonsurgical treatment of complicated appendicitis avoids a large colonic resection, is associated with a lower complication rate and shorter hospital stay, and has a success rate greater than $90 \%$ [3].

It remains controversial whether interval appendectomy should be performed after successful conservative management. While earlier studies of initial conservative treatment considered elective interval appendectomy part of the longitudinal treatment plan for complicated appendicitis, recent studies have questioned the need for this procedure. Some authors insist that routine performance of interval appendectomy should be abandoned because the recurrence rate of acute appendicitis treated nonsurgically is similar 
to or even lower than the initial lifetime risk of appendicitis [3-7]. On the basis of this low recurrence rate, these authors suggested that it is not necessary to accept the considerable morbidity and increased cost of interval appendectomy. The World Society of Emergency Surgery stated in its 2016 guidelines that, because of its consistent morbidity, interval appendectomy as a routine procedure following successful conservative management is justified only in cases of persistent or recurrent symptoms and should be avoided in asymptomatic patients [8].

However, some surgeons recommend interval appendectomy because of the potential that the appendicitis is associated with a hidden neoplasm. Although tumors are a relatively rare cause of acute appendicitis, several small studies have suggested increased risk of neoplasm after periappendiceal abscess, especially in patients older than 40 years [9-12]. If this is true, it would be an argument for interval appendectomy.

In this study, we aimed to identify the risk of neoplasm in the population undergoing interval appendectomy, together with the safety and effectiveness of interval appendectomy compared with immediate appendectomy.

\section{METHODS}

\section{Patient selection and data collection}

This study retrospectively analyzed a consecutive series of appendicitis cases that were treated with surgery between January 2014 and December 2018 at a single tertiary referral center. Patients aged 18 years and older at the time of the surgery were included in the analysis. The patients were divided into 2 groups depending on whether they underwent immediate or interval appendectomy. Interval appendectomy was defined as elective surgery following initial successful nonsurgical management consisting of antibiotic administration with or without percutaneous drainage of an abscess. The surgeons in charge of emergency surgery and follow-up during the study period routinely recommended and performed interval appendectomy in all patients treated successfully with nonsurgical management, except when the patient refused surgery. Interval appendectomy was generally recommended 4 to 6 weeks after initial treatment in the case of a small abscess. In the case of a larger abscess or phlegmon, interval appendectomy was recommended 12 weeks or more after initial treatment. However, the actual time of surgery was either advanced or delayed according to the patient's wishes. Abdominopelvic computed tomography scan was routinely performed during the follow-up period before surgery. However, colonoscopy was selectively performed when deemed necessary. Patient demographics and perioperative clinical and pathologic parameters were collected from an electronic medical record system. Postoperative morbidity and mortality within 30 days following surgery were investigated. Postoperative morbidity was defined as complications that required any additional treatment, prolonged hospital stay, or frequent outpatient clinic visits.
The primary outcome measure was rate of appendiceal neoplasm in patients undergoing interval surgical treatment. Secondary outcome measure was surgical outcome by group (immediate vs. interval).

\section{Statistical analysis}

Statistical analysis was performed using IBM SPSS ver. 24 (IBM Corp., Armonk, NY, USA). Continuous variables were compared using Student t-test or Mann-Whitney U-test, and categorical variables were analyzed using chi-square test or Fisher exact test. P-values $<0.05$ were considered significant.

\section{Ethics statement}

This retrospective study was approved by the Institutional Review Board of Kangbuk Samsung Hospital (No. KSH 2019-06-023), and informed consent was waived.

\section{RESULTS}

All 2,449 patients surgically treated because of acute appendicitis during the study period were identified. Of these patients, 436 under 18 years of age were excluded from the analysis. The mean age of the remaining 2,013 adult patients included in the analysis was 42.5 years (range, 18 to 94 years) (Table 1 ). Incidence rates by sex were similar but slightly higher in men $(51.4 \%, 1,034$ of 2,013$)$ than in women $(48.6 \%, 979$ of 2,013). Most of the procedures ( $99.1 \%, 1,995$ of 2,013) were completed laparoscopically, while 5 cases $(0.2 \%)$ were initiated laparoscopically and converted to open surgery. A planned open procedure was performed in 13 cases $(0.6 \%)$. Overall, $92.1 \%(1,854$ of 2,013$)$ of all procedures were completed by appendectomy whether the operative findings were simple $(65.8 \%, 1,324$ of 2,013) or complicated by either current or traces of previous perforation, abscess, or inflammatory adhesion $(26.3 \%, 530$ of 2,013). However, 159 patients (7.9\%) required additional resection including cecectomy (157 patients) and ileocecectomy or right hemicolectomy (2 patients). Interval appendectomy accounted for 5.5\% (111 of 2,013) of cases. The mean time to interval appendectomy was 10.2 weeks (range, 1 to 23 weeks) after initial treatment. In the interval group, 14 patients (12.6\%) underwent colonoscopy during the follow-up period before surgery, and there were no abnormal findings of appendiceal orifice or cecum in any of the cases. The mean length of postoperative hospital stay was 3.83 days (range, 1 to 48 days), the morbidity rate was $6.0 \%$ (120 of 2,013), and the most common complication was superficial surgical site infection $(4.4 \%, 88$ of 2,013$)$.

Patients in the interval group were older $(\mathrm{P}<0.001)$ and showed a trend toward higher American Society of Anesthesiologists (ASA) physical status classification $(\mathrm{P}<0.001)$. Extended procedures were also more commonly performed in the interval group $(\mathrm{P}<0.001)$. Cecectomy as a final procedure was performed in almost one-third of the patients $(29.7 \%, 33$ of 111$)$ in the interval group but in only $6.5 \%$ of those in the immediate group. However, in the interval 
Volume 36, Number 5, 2020

Table 1. Characteristics of patients who underwent immediate or interval surgical treatment for initial diagnosis of acute appendicitis

\begin{tabular}{|c|c|c|c|c|}
\hline Characteristic & $\begin{array}{c}\text { Total } \\
(\mathrm{n}=2,013)\end{array}$ & $\begin{array}{l}\text { Immediate } \\
(\mathrm{n}=1,902)\end{array}$ & $\begin{array}{l}\text { Interval } \\
(\mathrm{n}=111)\end{array}$ & P-value \\
\hline Age (yr) & $42.5 \pm 16.3$ & $41.9 \pm 16.0$ & $54.0 \pm 16.6$ & $<0.001$ \\
\hline Sex & & & & 0.848 \\
\hline Male & $1,034(51.4)$ & $976(51.3)$ & $58(52.3)$ & \\
\hline Female & 979 (48.6) & $926(48.7)$ & $53(47.7)$ & \\
\hline ASA PS classification & & & & $<0.001$ \\
\hline । & $1,422(70.6)$ & $1,367(71.9)$ & 55 (49.5) & \\
\hline$\|$ & $463(23.0)$ & $426(22.4)$ & 37 (33.3) & \\
\hline III & $126(6.3)$ & $107(5.6)$ & 19 (17.2) & \\
\hline IV & $2(0.1)$ & $2(0.1)$ & $0(0)$ & \\
\hline Operative approach & & & & $<0.001$ \\
\hline Conventional laparoscopy & $1,956(97.2)$ & $1,852(97.4)$ & $104(93.7)$ & \\
\hline Single-port laparoscopy & $39(1.9)$ & $34(1.8)$ & $5(4.5)$ & \\
\hline Conversion to HAL & $1(0.0)$ & 0 & $1(0.9)$ & \\
\hline Conversion to open & $4(0.2)$ & $4(0.2)$ & 0 & \\
\hline Open & $13(0.6)$ & $12(0.6)$ & $1(0.9)$ & \\
\hline Final procedure & & & & $<0.001$ \\
\hline Simple appendectomy & $1,324(65.8)$ & $1,281(67.4)$ & $43(38.7)$ & \\
\hline Perforated appendectomy & $530(26.3)$ & $496(26.1)$ & $34(30.6)$ & \\
\hline Cecectomy & $157(7.8)$ & $124(6.5)$ & $33(29.7)$ & \\
\hline $\begin{array}{l}\text { Ileocecectomy/right } \\
\text { hemi colectomy }\end{array}$ & $2(0.1)$ & $1(0.0)$ & $1(0.9)$ & \\
\hline Neoplasm & $36(1.8)$ & $22(1.2)$ & $14(12.6)$ & $<0.001$ \\
\hline $\begin{array}{l}\text { Postoperative hospital stay } \\
\text { (day) }\end{array}$ & $3.83 \pm 2.8$ & $3.8 \pm 2.8$ & $3.5 \pm 2.0$ & 0.140 \\
\hline Morbidity & $120(6.0)$ & $113(5.9)$ & $7(6.3)$ & 0.874 \\
\hline lleus & $21(1.0)$ & $19(1.0)$ & $2(1.8)$ & 0.324 \\
\hline Gastroenteritis & $15(0.7)$ & $15(0.8)$ & 0 & 1 \\
\hline $\begin{array}{l}\text { Superficial surgical site } \\
\text { infection }\end{array}$ & $88(4.4)$ & $83(4.4)$ & $5(4.5)$ & 0.813 \\
\hline Deep surgical site infection & $31(1.5)$ & $30(1.6)$ & $1(0.9)$ & 1 \\
\hline Mortality & 0 & 0 & 0 & \\
\hline
\end{tabular}

Values are presented as mean \pm standard deviation or number (\%).

ASA PS, American Society of Anesthesiologists physical status; HAL, hand assisted laparoscopy.

group, a larger proportion of the procedures was completed as single-port laparoscopy. The conversion rate was similar, and the rate of planned open procedures did not differ significantly between groups. Similarly, there was no significant difference between groups in duration of postoperative hospital stays or morbidity rate.

Appendiceal neoplasm was identified on pathologic analysis in 36 cases $(1.8 \%)$ (Table 2$)$. These included 27 low-grade appendiceal mucinous neoplasms (75.0\%), 3 mucinous adenocarcinomas
Table 2. Histologic types of neoplasms

\begin{tabular}{|c|c|c|c|c|}
\hline Histologic subtype & $\begin{array}{c}\text { Total } \\
(\mathrm{n}=2,013)\end{array}$ & $\begin{array}{l}\text { Immediate } \\
(\mathrm{n}=1,902)\end{array}$ & $\begin{array}{l}\text { Interval } \\
(\mathrm{n}=111)\end{array}$ & P-value \\
\hline \multicolumn{5}{|l|}{ Adenoma } \\
\hline Tubular adenoma & 2 & 2 & 0 & \\
\hline \multicolumn{5}{|l|}{ Serrated lesion } \\
\hline Hyperplastic polyp & 1 & 1 & 0 & \\
\hline Sessile serrated adenoma & 1 & 1 & 0 & \\
\hline \multicolumn{5}{|l|}{ Neuroendocrine neoplasms } \\
\hline Neuroendocrine tumor G1 & 1 & 1 & 0 & \\
\hline Goblet cell carcinoid & 1 & 1 & 0 & \\
\hline \multicolumn{5}{|l|}{ Carcinoma } \\
\hline $\begin{array}{l}\text { Mucinous adenocarci- } \\
\text { noma }\end{array}$ & 3 & 1 & 2 & \\
\hline $\begin{array}{l}\text { Low-grade appendiceal } \\
\text { mucinous neoplasm }\end{array}$ & 27 & 15 & 12 & \\
\hline Total & $36(1.8)$ & $22(1.2)$ & $14(12.6)$ & $<0.001$ \\
\hline
\end{tabular}

(8.3\%), 2 tubular adenomas (5.6\%), 2 neuroendocrine tumors (NETs, 5.6\%), 1 hyperplastic polyp (1.8\%), and 1 sessile serrated adenoma (1.8\%). Most of the neoplasms were mucinous. The incidence of neoplasm in the interval group was 12.6\% (14 of 111), which was significantly higher than that in the immediate group (1.2\% [ 22 of 1,902$], \mathrm{P}<0.001)$. When comparing the interval group and the subset of patients from the immediate group with complicated appendicitis $(n=621)$, the incidence of neoplasm was still significantly different between the 2 groups; $12.6 \%$ and $2.2 \%$, respectively, with the interval group having the higher incidence. When the patients were divided into 5-year age groups, no cases of neoplasm were seen in the $<35$ years old group, and the incidence of neoplasms tended to increase with age, being especially high in the $\geq 60$ years old groups (Table 3 ). Overall, the incidence rate of neoplasms in patients aged $\geq 40$ years ( $3.3 \%, 35$ of $1,054)$ was significantly higher than that in patients aged $<40$ years $(0.1 \%$ [ 1 of 959$]$; $\mathrm{P}<0.001)$.

\section{DISCUSSION}

For over a century, the gold standard treatment for acute appendicitis was immediate surgery. Recently, interval appendectomy following initial conservative nonsurgical management emerged as a potentially better treatment option for complicated appendicitis. This protocol avoids the possibility of increased morbidity and more extensive surgery in the acute situation due to the impaired general condition of the patients and the presence of inflamed and friable tissue. Initial nonsurgical management has become the standard treatment option for complicated appendicitis, with a high success rate greater than $90 \%$ [3].

More recently, the need for interval appendectomy following 


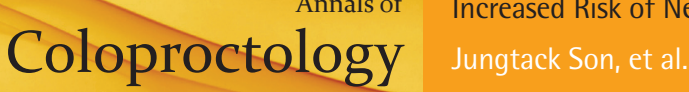

Table 3. Incidence of appendiceal neoplasm by age $(n=2,013)$

\begin{tabular}{|c|c|c|c|c|c|c|c|c|c|c|c|c|c|}
\hline \multirow[t]{2}{*}{ Variable } & \multicolumn{9}{|c|}{$\begin{array}{l}\text { Age group (yr), } \\
5 \text {-yr interval }\end{array}$} & \multirow[t]{2}{*}{ P-value } & \multicolumn{2}{|c|}{$\begin{array}{l}\text { Age group (yr), } \\
<40, \geq 40\end{array}$} & \multirow[t]{2}{*}{ P-value } \\
\hline & $<35$ & $35-39$ & 40-44 & $45-49$ & $50-54$ & $55-59$ & $60-64$ & $65-69$ & $>70$ & & $<40$ & $\geq 40$ & \\
\hline Patient & $765(38.0)$ & $194(9.6)$ & $211(10.5)$ & $202(10.0)$ & $154(7.7)$ & $151(7.5)$ & $104(5.2)$ & $82(4.1)$ & $150(7.5)$ & $<0.001$ & $959(47.6)$ & $1,054(52.4)$ & $<0.001$ \\
\hline Neoplasm & 0 & $1(0.5)$ & $4(1.9)$ & $3(1.5)$ & $1(0.6)$ & $5(3.3)$ & $8(7.7)$ & $3(3.7)$ & $11(7.3)$ & & $1(0.1)$ & $35(3.3)$ & \\
\hline
\end{tabular}

Values are presented as number (\%).

successful nonsurgical management has been questioned. In the early days, interval appendectomy was routinely performed because of concerns about disease recurrence. However, with several reports demonstrating a similar or even lower recurrence rate than the initial incidence of acute appendicitis, the argument that routine interval appendectomy should be omitted to avoid the cost and risk of surgery became stronger [3-8].

However, some surgeons insist that the real danger of abandoning interval appendectomy is not recurrence of appendicitis, but rather absence of appendiceal pathological analysis. Although relatively rare, appendiceal neoplasms occur at a rate of $0.7 \%$ to $1.7 \%$ in large series of appendectomies [13-16]. Because of the unique anatomic characteristics of the appendix, appendiceal neoplasms that are too small to be seen on imaging can infiltrate through the wall or obstruct the lumen, leading to acute inflammation and distal perforation. Acute appendicitis is the most common initial presentation of an appendiceal neoplasm that has not been diagnosed preoperatively, accounting for more than $50 \%$ of all cases $[15,16]$. Recently, several studies have suggested increased risk of neoplasms after a periappendiceal abscess [9-12], which is currently usually initially treated without surgery, followed by, in some cases, planned interval appendectomy.

This study produced a $1.8 \%$ overall incidence of appendiceal tumors in all patients undergoing surgical treatment for a presumed diagnosis of appendicitis at a single tertiary center, which is slightly higher than previously reported [13-16]. In patients who underwent interval appendectomy for complicated appendicitis, the incidence of appendiceal tumors was $12.6 \%$, which was significantly higher than the $1.2 \%$ incidence after immediate appendectomy. This difference did not change even when the interval group was compared to the subset of patients from the immediate group with complicated appendicitis; the incidence of neoplasm in the interval group was significantly higher.

The neoplasms commonly found in the appendix are epithelial tumors, including mucinous neoplasms, and NETs. According to a previous report, the prevalence of NET among all appendectomy specimens was $0.3 \%$ to $0.9 \%$, that of epithelial tumors was $0.2 \%$ to $0.3 \%$, and mucinous neoplasms accounted for $70 \%$ [17]. In this study, the most common neoplastic pathology was low-grade appendiceal mucinous neoplasm, which accounted for $75 \%$ of all neoplastic lesions. It could be argued that the increased incidence of these neoplasms in interval appendectomy cases is not a significant threat because of the low-grade of these tumors. However, advanced NET has an unfavorable prognosis, with a 5-year survival rate of $12 \%$ to $28 \%$ [18], while undiagnosed mucinous neoplasms can manifest as pseudomyxoma peritonei, which not only affects patient survival, but also significantly impairs quality of life [19]. More importantly, our study clearly identified true malignancies, such as mucinous cystadenocarcinoma and adenocarcinoma, which could not be distinguished from 'low-grade tumors' in the appendix before surgical resection and pathologic examination.

Although there is an increasing number of reports describing the incidence of neoplastic disease in patients undergoing interval appendectomy, it is difficult to find reports about the incidence of neoplastic disease diagnosed in patients followed up without surgical treatment after initial conservative management. This is probably because, like most other benign inflammatory diseases, patients are not followed closely after treatment of appendicitis, and follow-up rarely includes imaging. Even when the patient does undergo imaging, the follow-up ends after confirmation of resolved inflammation. With this in mind, Mallinen et al. [11] aimed to define the risk of neoplastic disease in patients who underwent interval appendectomy or follow-up only after initial successful nonsurgical treatment of complicated appendicitis. They randomly assigned such patients to interval appendectomy or follow-up only, with the latter group undergoing regular serial magnetic resonance imaging and colonoscopy. However, the trial was prematurely terminated because, at the time of interim analysis, one-third of the patients in the follow-up group required surgery. The $30 \%$ of patients in the follow-up group who underwent surgery were operated on because of a pathological imaging finding, which accounted for $10 \%$ of the neoplastic disease incidence in the follow-up group. Thus, contrary to the initial hypothesis of the study that 'interval appendectomy is not necessary', the authors concluded that interval appendectomy should be considered after initial successful treatment of a periappendiceal abscess.

Most studies that have reported an increased risk of neoplasm in patients having initial complicated appendicitis or interval appendectomy indicate that an age of 40 years or older is a risk factor for neoplastic disease [10-12]. In the present study, the incidence rate of neoplasms in patients over 40 years was much higher than that of patients under 40 years of age, and no neoplasms were identified in patients younger than 35 years, supporting the results of previous studies. The rate of appendiceal neoplasm in patients older than 40 years should be further evaluated in prospective cohort studies of patients undergoing interval appendectomy 
because the procedure is generally well tolerated and eliminates the risk of missing a possible tumor. In the present study, the morbidity of the interval group was similar to that of the immediate appendectomy group, although the general condition of the patients in the interval group, as indicated by ASA physical status classification, was significantly worse. Moreover, most of the complications were superficial surgical site infections, which can easily be controlled in outpatient clinics.

In conclusion, although most of the tumors were low-grade, the increased incidence of neoplastic disease in the interval group may have clinical significance. Surgeons should consider interval appendectomy as a viable treatment option after successful conservative management in adult patients, especially those aged 40 years or older. When the patient chooses not to undergo surgery after successful initial conservative treatment, serial follow-up with imaging studies might be a better option than abrupt termination of follow-up.

\section{CONFLICT OF INTEREST}

No potential conflict of interest relevant to this article was reported.

\section{REFERENCES}

1. Ellis H. Reginald Fitz: father of appendicitis. Br J Hosp Med (Lond) 2013;74:534.

2. Health Insurance Review and Assessment Service. Healthcare Bigdata Hub [Internet]. Wonju (Korea): Health Insurance Review and Assessment Service; c2015 [cited 2019 Aug 27]. Available from: https://opendata.hira.or.kr/home.do.

3. Andersson RE, Petzold MG. Nonsurgical treatment of appendiceal abscess or phlegmon: a systematic review and meta-analysis. Ann Surg 2007;246:741-8.

4. Kaminski A, Liu IL, Applebaum H, Lee SL, Haigh PI. Routine interval appendectomy is not justified after initial nonoperative treatment of acute appendicitis. Arch Surg 2005;140:897-901.

5. Darwazeh G, Cunningham SC, Kowdley GC. A systematic review of perforated appendicitis and phlegmon: interval appendectomy or wait-and-see? Am Surg 2016;82:11-5.

6. Deakin DE, Ahmed I. Interval appendicectomy after resolution of adult inflammatory appendix mass: is it necessary? Surgeon 2007; 5:45-50.

7. Sakorafas GH, Sabanis D, Lappas C, Mastoraki A, Papanikolaou J, Siristatidis $\mathrm{C}$, et al. Interval routine appendectomy following conservative treatment of acute appendicitis: is it really needed. World
J Gastrointest Surg 2012;4:83-6.

8. Di Saverio S, Birindelli A, Kelly MD, Catena F, Weber DG, Sartelli $\mathrm{M}$, et al. WSES Jerusalem guidelines for diagnosis and treatment of acute appendicitis. World J Emerg Surg 2016;11:34.

9. Carpenter SG, Chapital AB, Merritt MV, Johnson DJ. Increased risk of neoplasm in appendicitis treated with interval appendectomy: single-institution experience and literature review. Am Surg 2012;78:339-43.

10. Furman MJ, Cahan M, Cohen P, Lambert LA. Increased risk of mucinous neoplasm of the appendix in adults undergoing interval appendectomy. JAMA Surg 2013;148:703-6.

11. Mallinen J, Rautio T, Gronroos J, Rantanen T, Nordstrom P, Savolainen H, et al. Risk of appendiceal neoplasm in periappendicular abscess in patients treated with interval appendectomy vs follow-up with magnetic resonance imaging: 1-year outcomes of the peri-appendicitis acuta randomized clinical trial. JAMA Surg 2019;154:200-7.

12. Wright GP, Mater ME, Carroll JT, Choy JS, Chung MH. Is there truly an oncologic indication for interval appendectomy? Am J Surg 2015;209:442-6.

13. Charfi S, Sellami A, Affes A, Yaich K, Mzali R, Boudawara TS. Histopathological findings in appendectomy specimens: a study of 24,697 cases. Int J Colorectal Dis 2014;29:1009-12.

14. Smeenk RM, van Velthuysen ML, Verwaal VJ, Zoetmulder FA. Appendiceal neoplasms and pseudomyxoma peritonei: a population based study. Eur J Surg Oncol 2008;34:196-201.

15. Lee WS, Choi ST, Lee JN, Kim KK, Park YH, Baek JH. A retrospective clinicopathological analysis of appendiceal tumors from 3,744 appendectomies: a single-institution study. Int J Colorectal Dis 2011;26:617-21.

16. Connor SJ, Hanna GB, Frizelle FA. Appendiceal tumors: retrospective clinicopathologic analysis of appendiceal tumors from 7,970 appendectomies. Dis Colon Rectum 1998;41:75-80.

17. Limaiem F, Arfa N, Marsaoui L, Bouraoui S, Lahmar A, Mzabi S. Unexpected histopathological findings in appendectomy specimens: a retrospective study of 1627 cases. Indian J Surg 2015;77: 1285-90.

18. Garcia-Carbonero R, Capdevila J, Crespo-Herrero G, Diaz-Perez JA, Martinez Del Prado MP, Alonso Orduna V, et al. Incidence, patterns of care and prognostic factors for outcome of gastroenteropancreatic neuroendocrine tumors (GEP-NETs): results from the National Cancer Registry of Spain (RGETNE). Ann Oncol 2010; 21:1794-803.

19. Smeenk RM, Bruin SC, van Velthuysen ML, Verwaal VJ. Pseudomyxoma peritonei. Curr Probl Surg 2008;45:527-75. 